\title{
Inhibition of Angiotensin Converting Enzyme Impairs Anti-staphylococcal Immune Function in a Preclinical Model of Implant Infection
}

\author{
Rishi Trikha ${ }^{1}$, Danielle Greig ${ }^{1}$, Benjamin V. Kelley ${ }^{1}$, Zeinab Mamouei ${ }^{1}$, Troy Sekimura ${ }^{1}$, \\ Nicolas Cevallos ${ }^{1}$, Thomas Olson ${ }^{1}$, Ameen Chaudry ${ }^{1}$, Clara Magyar ${ }^{1}$, Daniel Leisman ${ }^{2}$, \\ Alexandra Stavrakis ${ }^{1}$, Michael R. Yeaman ${ }^{3,4}$ and Nicholas M. Bernthal ${ }^{1 *}$ \\ ${ }^{1}$ Department of Orthopaedic Surgery, University of California, Los Angeles, CA, United States, ${ }^{2}$ Icahn School of Medicine at \\ Mount Sinai, New York, NY, United States, ${ }^{3}$ Divisions of Molecular Medicine and Infectious Diseases, Department of \\ Medicine, Harbor-UCLA Medical Center, Torrance, CA, United States, ${ }^{4}$ The Lundquist Institute for Biomedical Innovation at \\ Harbor-UCLA Medical Center, Torrance, CA, United States
}

OPEN ACCESS

Edited by:

Semih Esin,

University of Pisa, Italy

Reviewed by:

Nihal Engin Vrana,

Sparta Medical, France

Hridayesh Prakash,

Amity University, India

*Correspondence:

Nicholas M. Bernthal

nbernthal@mednet.ucla.edu

Specialty section:

This article was submitted to

Microbial Immunology,

a section of the journal

Frontiers in Immunology

Received: 07 May 2020

Accepted: 16 July 2020

Published: 11 September 2020

Citation:

Trikha R, Greig D, Kelley BV, Mamouei Z, Sekimura T, Cevallos $N$

Olson T, Chaudry A, Magyar C, Leisman D, Stavrakis A, Yeaman MR and Bernthal NM (2020) Inhibition of

Angiotensin Converting Enzyme Impairs Anti-staphylococcal Immune

Function in a Preclinical Model of Implant Infection.

Front. Immunol. 11:1919. doi: 10.3389/fimmu.2020.01919
Background: Evidence suggests the renin-angiotensin system (RAS) plays key immunomodulatory roles. In particular, angiotensin-converting enzyme (ACE) has been shown to play a role in antimicrobial host defense. ACE inhibitors (ACEi) and angiotensin receptor blockers (ARB) are some of the most commonly prescribed medications, especially in patients undergoing invasive surgery. Thus, the current study assessed the immunomodulatory effect of RAS-modulation in a preclinical model of implant infection.

Methods: In vitro antimicrobial effects of ACEi and ARBs were first assessed. C57BL/6J mice subsequently received either an ACEi (lisinopril; 16 mg/kg/day), an ARB (losartan; $30 \mathrm{mg} / \mathrm{kg} /$ day), or no treatment. Conditioned mice blood was then utilized to quantify respiratory burst function as well as Staphylococcus aureus Xen36 burden ex vivo in each treatment group. S. aureus infectious burden for each treatment group was then assessed in vivo using a validated mouse model of implant infection. Real-time quantitation of infectious burden via bioluminescent imaging over the course of 28 days post-procedure was assessed. Host response via monocyte and neutrophil infiltration within paraspinal and spleen tissue was quantified by immunohistochemistry for F4/80 and myeloperoxidase, respectively.

Results: Blood from mice treated with an ACEi demonstrated a decreased ability to eradicate bacteria when mixed with Xen36 as significantly higher levels of colony forming units (CFU) and biofilm formation was appreciated ex vivo $(p<0.05)$. Mice treated with an ACEi showed a higher infection burden in vivo at all times $(p<0.05)$ and significantly higher CFUs of bacteria on both implant and paraspinal tissue at the time of sacrifice ( $p<0.05$ for each comparison). There was also significantly decreased infiltration and respiratory burst function of immune effector cells in the ACEi group $(p<0.05)$.

Conclusion: $\mathrm{ACE}$, but not $\mathrm{ARB}$, treatment resulted in increased $S$. aureus burden and impaired immune response in a preclinical model of implant infection. These results 
suggest that perioperative ACEi use may represent a previously unappreciated risk factor for surgical site infection. Given the relative interchangeability of ACEi and ARB from a cardiovascular standpoint, this risk factor may be modifiable.

Keywords: implant, infection, angiotensin-converting enzyme inhibitor, angiotensin II receptor blocker, bioluminescence

\section{INTRODUCTION}

Implant-associated surgical site infections (SSI) represent significant morbidity and mortality for the patient as well as massive economic strain to the current healthcare system (1-7). Despite increasing efforts to prevent SSI through perioperative antibiotic management and the optimization of aseptic surgical technique, infection rates still range from $1.2 \%$ in primary joint replacements to $8.6 \%$ in ventral hernia mesh repair to as high as $12.9 \%$ in ventriculoperitoneal shunts (8-16). Although infection rates and treatment approaches vary by implant type, the overwhelming majority of patients who develop SSI ultimately require surgical implant removal, as bacteria form protective glycocalyx layers on avascular surfaces knows as biofilm $(8,17,18)$. In high risk surgeries such as cardiac device implantation and spinal instrumentation, this can lead to catastrophic outcomes such as cardiovascular compromise, spinal column collapse, or death $(19,20)$. Even in hip and knee replacement surgery, an implant infection carries a worse 5 -year mortality rate than breast cancer, renal cell cancer, or HIV/AIDS (21-25). Given the absence of effective treatment for implant infections, prevention is thus paramount. To that end, the identification and optimization of safe and short-term hosttargetable risk factors represent crucial, innovative opportunities to prevent SSI.

Angiotensin-converting enzyme inhibitors (ACEi), which block the conversion of angiotensin I to angiotensin II, and angiotensin II receptor blockers (ARB) are two of the most commonly used drugs for the treatment of hypertension (2629). In 2017, 73 million Americans were prescribed at least one cardiovascular medication, of which, 28 million Americans were prescribed an ACEi and another 15 million were prescribed an ARB (30). Furthermore, according to the CDC, an estimated $11.4 \%$ of Americans between 40 and 59 years old, and $21.3 \%$ from the age of 60-79 have taken an ACEi in the last 30 days (31). The prevalence of these medications is perhaps even greater in the surgical population. In one multi-institutional study performed across 12 surgery centers, 4,802 out of 14,687 (32.7\%) patients who underwent inpatient non-cardiac surgery were taking an ACEi or ARB perioperatively (32).

While the role of the renin-angiotensin system for blood pressure regulation is well-known, emerging evidence suggests this system also has an immunologic function. Of the components involved in this system, ACE appears to have a particularly important role in antimicrobial host defense. Multiple human and animal studies have demonstrated that ACE overexpression increases immune cell response and facilitates host defense against bacterial infections (26, 33-46). In one murine study, selectively reducing ACE expression in neutrophils led to a 6-fold reduction in the clearance of a subcutaneous infection with methicillin-resistant Staphylococcus aureus (MRSA) (26). The purported mechanisms underlying any possible immunosuppressive effect of ACE inhibition include dysregulation of TNF- $\alpha$, IL- 6 and/or TGF- $\beta$ response $(47,48)$, IL12 suppression (49), decreased neutrophil superoxide production (26), dysfunctional macrophage activity (34, 35, 40), impaired chemotactic function (34), and decreased pro-inflammatory cytokine production $(39,40)$. Such mechanisms may impact innate and/or adaptive roles of antimicrobial host defense.

It is crucial to ensure immunocompetency at the time of surgery as the immunoprofile of patients prior to implantation are inextricably linked with the development of a SSI (50-52). It is undoubtedly true that certain patients will not be able to achieve lifelong immunocompetency, however the optimization of the immune system at the time of surgery remains vitally important to minimize SSI, as the majority of implant associated infections occur at the time of surgery $(51,52)$. Although the immunological impact of ACEi has been studied, to some extent, in vitro and in short-term models in vivo (33-35, 38, 40$42,46)$, there is a lack of longitudinal in vivo data to quantify this effect or explore its potential mechanistic basis, and no study to our knowledge has investigated this phenomenon in a surgical model. Thus, the purpose of this study was to assess whether perioperative ACEi treatment impacts the host immune response and determine whether any purported impact would be sufficient to affect infection rates and severity in a wellvalidated in vivo mouse model of implant infection (53-56). This study also aimed to assess whether a reasonable alternative drug with a similar cardiovascular profile could avoid such host immunomodulation, thus optimizing host immunity to minimize perioperative infectious risk.

\section{MATERIALS AND METHODS}

\section{Ethics Statement}

All animal studies were performed in accordance with protocols reviewed and approved by the Chancellor's Animal Research Committee (ARC) at University of California, Los Angeles (ARC \#2012-104-21J). These practices are adherent to National Institute of Health and Public Health Service policies.

\section{Selection and Preparation of Bioluminescent Xen36 Staphylococcus aureus}

Staphylococcus aureus strain Xen36 (PerkinElmer, Waltham, MA), a bioluminescent strain derived from ATCC-29525 (Wright), was used as the study organism. This strain 
expresses a genomically integrated luxABCDE operon $(53,57$, 58). Consequently, Xen 36 generates a bioluminescent bluegreen signal with a maximal emission wavelength of $490 \mathrm{~nm}$ from viable, metabolically active organisms. Previous studies demonstrated this strain to be ideal for research targeting the longitudinal monitoring of $S$. aureus infections due to its strength and consistency of signal (57-59).

Bacterial inocula were prepared following previously published protocols (53-57). In brief, Xen36 was isolated on kanamycin to select for purity and affirm possession of the kanamycin-resistance marker integral to the lux operon. The authenticated Xen36 strain was then quadrant-streaked onto tryptic soy agar (TSA; Beckton-Dickinson) and incubated for $24 \mathrm{~h}$ at $37^{\circ} \mathrm{C}$. Single colonies were then isolated and cultured in tryptic soy broth (TSB) for $16 \mathrm{~h}$ at $37^{\circ} \mathrm{C}$ in a shaking incubator (196 rpm) (MaxQ 4,450, Thermo). A subsequent $2 \mathrm{~h}$ subculture of a 1:50 dilution of this culture was used to obtain a midlogarithmic phase bacteria. Lastly, after centrifugation, cells were pelleted, resuspended, and washed in PBS. Bacterial inocula were quantitated and standardized by spectrophotometry (OD, $600 \mathrm{~nm}$; BioMate 3; ThermoFisher Scientific). A schematic overview of our ex vivo and in vivo experiments is provided (Figure 1).

\section{In vitro Determination of Direct Staphylococcal Growth Effect of ACEi or ARB}

In order to confirm that ACEi or ARB do not have any direct antimicrobial effects against $S$. aureus, a Kirby Bauer diffusion susceptibility test was performed (60). Briefly, $20 \mu \mathrm{L}$ of ACEi,
$\mathrm{ARB}$, vancomycin, each at a concentration of $0.5 \mathrm{mg} / \mathrm{mL}$, or normal saline was aliquoted onto separate $6 \mathrm{~mm}$ filter paper disks and left to dry for $30 \mathrm{~min}$. One disk from each group was then placed into a separate quadrant of a TSA plate that had been flooded and spread with $200 \mu \mathrm{L}$ of $1 \times 10^{6} \mathrm{~S}$. aureus Xen36. This was performed for four total plates. This procedure was replicated on four additional plates using a concentration of $1 \mathrm{mg} / \mathrm{mL}$ of study therapeutics. Plates were left to incubate at $37^{\circ} \mathrm{C}$ for $16 \mathrm{~h}$ and zone of inhibition(s) were then analyzed.

\section{Mice and Medication Administration}

Eight to twelve-week-old, 20-25g C57BL/6 wildtype mice (Jackson Laboratories, Bar Harbor, ME) were housed (four mice per standard cage) and stored with a $12 \mathrm{~h}$ light and dark cycle with food and water ad libitum. Veterinary staff assessed all mice on a daily basis to ensure well-being throughout the entirety of the experiment.

Mice were randomized to receive treatment with either: an ACEi (lisinopril; 16 mg/kg/day PO; LKT Laboratories, St. Paul, $\mathrm{MN}$ ) (ACEi group), an ARB (losartan; $30 \mathrm{mg} / \mathrm{kg} /$ day PO, LKT Laboratories, St. Paul, MN) (ARB group), or no treatment (control group) with dosing as per prior independent protocols that demonstrated a percent reduction in blood pressure akin to that of humans $(40,61)$. Medications were suspended in $250 \mathrm{~mL}$ containers of drinking water. Ten milliliters of sucralose was added to the drinking water of all mice and intake was recorded daily to ensure each mouse drank 3-5 mL/day. For all ex vivo experiments, mice received medication treatment for 4 weeks prior to cardiac puncture and sacrifice. For in vivo

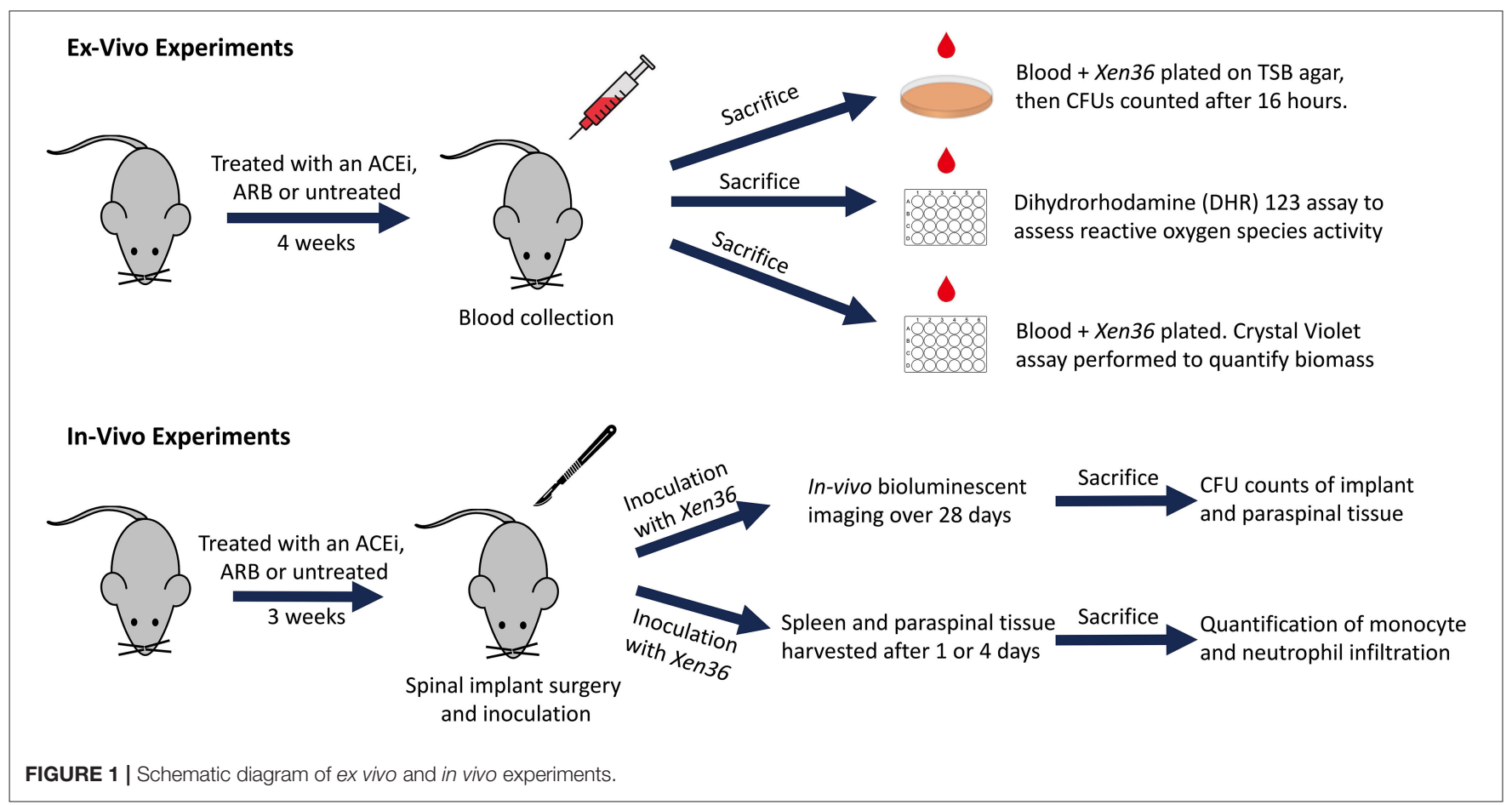


experiments, treatment began three weeks preoperatively and continued postoperatively for 4 weeks until sacrifice. These time points were selected based on previous studies demonstrating sufficiently altered immune profiles of mice blood after 7-10 days $(26,35)$.

\section{Ex vivo Quantification of Respiratory Burst}

Following 4 weeks of medication treatment, blood was collected from six mice in each group via cardiac puncture under $2 \%$ isoflurane inhalation anesthesia, followed by immediate euthanasia. Ethylenediaminetetraacetic acid (EDTA) was added to blood samples in a 1:10 ratio to prevent coagulation. Onehundred microliters were added from each mouse to each well within a 96-well flat bottom plate (Corning Costar, Corning, New York). Reactive oxygen species (ROS) activity of whole blood were assessed using a dihydrorhodamine (DHR) 123 assay. Briefly, $10 \mu \mathrm{L}$ of DHR 123 Assay Reagent followed by $25 \mu \mathrm{L}$ of Phorbol myristate acetate followed by $2 \mathrm{~mL}$ of Red Blood Cell Lysis Buffer was added to each plate. Mean fluorescent intensity was read with an excitation filter of $485 \mathrm{~nm}$ and an emission filter of $520 \mathrm{~nm}$ using a fluorescent plate reader (FLUOstar Omega, BMG Labtech, Ortenberg, Germany).

\section{Ex vivo CFU Quantification of S. aureus Mixed With Whole Blood}

Six mice in each group underwent whole blood collection as above. Ten microliters of blood from each mouse were then gently mixed with $10 \mu \mathrm{L}$ of $1 \times 10^{3} \mathrm{~S}$. aureus Xen36 and incubated at $37^{\circ} \mathrm{C}$ for $1 \mathrm{~h}$. After $1 \mathrm{~h}$, the entire $20 \mu \mathrm{L}$ of solution was quantitatively cultured on TSA and incubated at $37^{\circ} \mathrm{C}$ for 16 h. Resulting CFUs were then counted for a minimum of $n=6$ replicates in each group.

\section{Ex vivo Quantification of the Biofilm Biomass}

Five mice in each group underwent whole blood collection as above. One-hundred microliters of whole blood from each mouse were mixed with $100 \mu \mathrm{L}$ of $1 \times 10^{7} \mathrm{~S}$. aureus Xen $36 \mathrm{CFU} / \mathrm{mL}$ for a final inoculum of $10^{6} \mathrm{CFU}$ in $200 \mu \mathrm{L}$. This solution was added to each well within a 96-well-flat bottom plate. Six additional control wells containing $200 \mu \mathrm{L}$ of saline were also included for standardization. After $24 \mathrm{~h}$ of incubation at $37^{\circ} \mathrm{C}$, each well was washed with PBS three times to remove residual blood cells and non-adherent bacteria. A well-validated crystal violet assay (Abcam, Cambridge, United Kingdom) (62-64) was performed to quantify the biomass of the residual biofilm formation by $\mathrm{OD}$ at $595 \mathrm{~nm}$.

\section{In vivo and Longitudinal Monitoring of Bacterial Burden and Implant and Paraspinal Tissue CFU Quantification}

Twenty-six total mice were randomized into the following groups: 2 in the sterile control group, 8 in the infected control group, 8 in the ACEi group and 8 in the ARB group. Mouse spinal implant surgery and inoculation with $1 \times 10^{2} \mathrm{~S}$. aureus Xen36 was performed as described in prior protocols (53-56). Briefly, a midline dorsal incision was made and dissection was performed through the fascia and muscle directed laterally along the L4 spinous process. The L4 process was manually reamed with a 25-gauge needle. An "L-shaped" surgical grade $0.1 \mathrm{~mm}$ diameter titanium implant (Custom Wire Technologies, Port Washington, WI) was then press-fit into the L4 process. The long arm of the implant measured $6.5 \mathrm{~mm}$ in length and the short arm measured $3.5 \mathrm{~mm}$ in length (Figure 2). The IVIS Lumina X5 (PerkinElmer, Waltham, MA) was used to capture bioluminescent images representative of $S$. aureus Xen36 burden
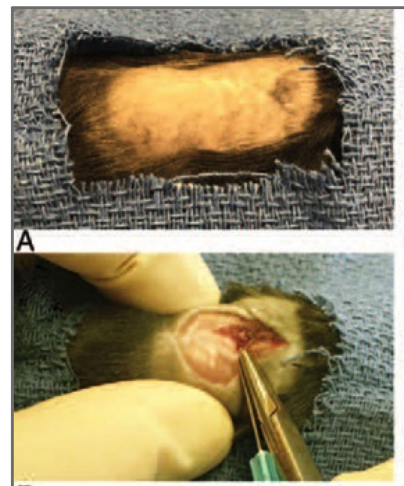

D
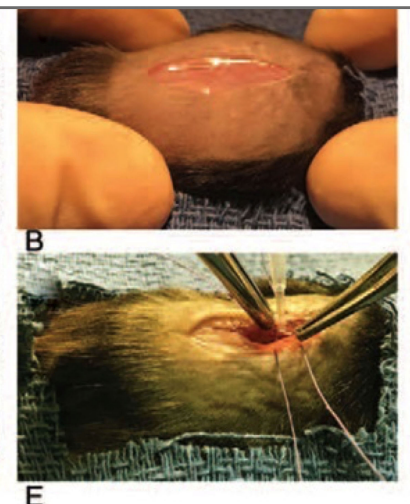
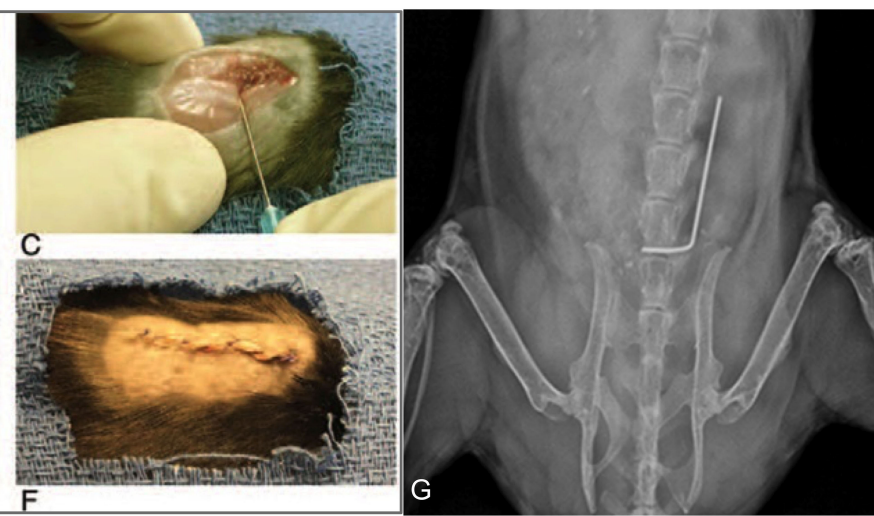

FIGURE 2 | Mouse spinal implant surgery procedures. (A) Mice were prepped with six alternating scrubs of povidone-iodine and alcohol and subsequently draped in a sterile fashion. (B) A $2 \mathrm{~cm}$ midline dorsal incision was made. Dissection was carried through the fascia and muscle and directed laterally along the L4 spinous process. (C) The $L 4$ spinous process was reamed with a 25 -gauge needle. (D) The short arm of the implant was press-fit into the spinous process and the long arm was laid longitudinally parallel along the spine directed cranially. (E) The wound was then prepared for closure using polyglycolic acid 5-0 sutures. Prior to these sutures being tied, $1 \times 10^{2} \mathrm{CFUs}$ of Xen36 in a volume of $2 \mu \mathrm{L}$ was inoculated directly onto the long arm of the implant. (F) Deep sutures were then tied and a running 5-0 vicryl suture was used to close the skin. (G) Proper placement of the implant was confirmed with high resolution X-rays on post-operative day 0 using the IVIS Lumina X5 (PerkinElmer, Waltham, MA). 
on postoperative day (POD) $0,1,3,5,7,10,14,18,21,25$, and 28. Bioluminescent quantification of bacterial burden was confirmed directly by CFU quantification of the implant and surrounding tissue. On POD 28, each mouse was sacrificed and CFU of bacteria adherent to the implant as well as in the paraspinal tissue quantified. To do so, the implant was sonicated in $500 \mu \mathrm{L}$ 0.3\% Tween-80 (ThermoFisher Scientific) in TSB and the paraspinal tissue was homogenized (Pro200H Series homogenizer; Pro Scientific). Samples from implants and paraspinal tissue were then plated onto a TSA plate and incubated overnight. Resulting CFUs per plate were counted and total CFUs harvested from the paraspinal tissue and implant were expressed as CFUs/mL.

\section{Histologic Analysis and Quantification of Monocyte and Neutrophil Infiltration}

An additional 12 mice were randomized into the following groups: four in the infected control group, four in the ARB group and four in the ACEi group. Mice underwent spinal implant surgery and infection as described above. Two mice in each group were sacrificed on POD1 and two mice in each group were sacrificed at POD4. At the time of sacrifice, paraspinal and splenic tissue samples were harvested and stained with hematoxylin and eosin (H\&E), F4/80 antibody (representing monocyte infiltration), and myeloperoxidase (MPO) (representing neutrophil infiltration). Histologic images were de-identified and qualitatively reviewed by a board-certified pathologist to assess for F4/80 and MPO signals. Brightfield slides were digitized on a ScanScope AT (Leica Biosystems, Inc., Vista, CA) and morphometric analysis performed with Definiens Tissue Studio (Definiens Inc., Parsippany,
NJ) to quantify monocyte and neutrophil counts. Briefly, a stain specific algorithm was created using the pre-defined cellular detection module and classification tool, through which positive and negative stained cells within a tissue core were identified. The data were exported to Excel for further statistical analysis.

\section{Statistical Analysis}

Probability $(p)$ values were calculated using a Student's $t$ test (one or two-tailed where indicated), while data analysis among three or more groups were compared using a oneway ANOVA. Longitudinal bioluminescent data were analyzed using a linear mixed effects regression model. Data were expressed as mean \pm standard error of the mean (SEM). Stata-14 software (Statacorp, College Station, TX) was used for all statistical analyses and statistical significance was set at $p<0.05$.

\section{RESULTS}

\section{In vitro Determination of Direct Staphylococcal Growth Effect of ACEi or ARB}

No zones of inhibition were appreciated in any plates for the normal saline, ACEi or ARB disks at any concentrations. A zone of inhibition of $18.5 \pm 0.3 \mathrm{~mm}$ was measured around disks with $0.5 \mathrm{mg} / \mathrm{mL}$ of vancomycin. A zone of inhibition of $20.5 \pm 0.3 \mathrm{~mm}$ was measured around disks with $1.0 \mathrm{mg} / \mathrm{mL}$ of vancomycin (Figures 3A,B).
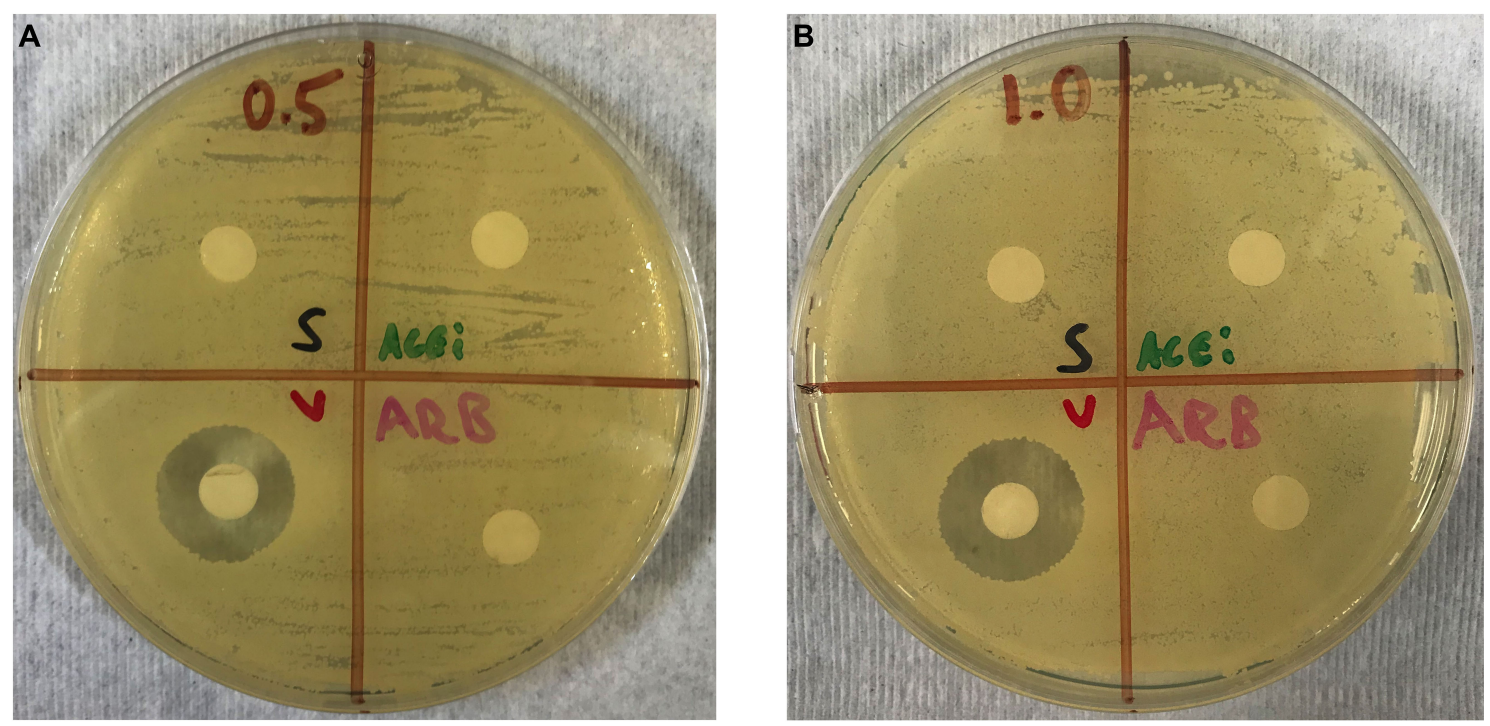

FIGURE 3 | Kirby-Bauer disk diffusion susceptibility test showing no direct effect of ACEi or ARB on S. aureus growth when study therapeutics are dosed at 0.5 $\mathrm{mg} / \mathrm{mL} \mathbf{( A )}$ and $1.0 \mathrm{mg} / \mathrm{mL}$ (B). Thus, any purported effect on bacterial burden in ACEi and ARB-treated mice were not due to any anti-staphylococcal properties of the therapeutics themselves. 


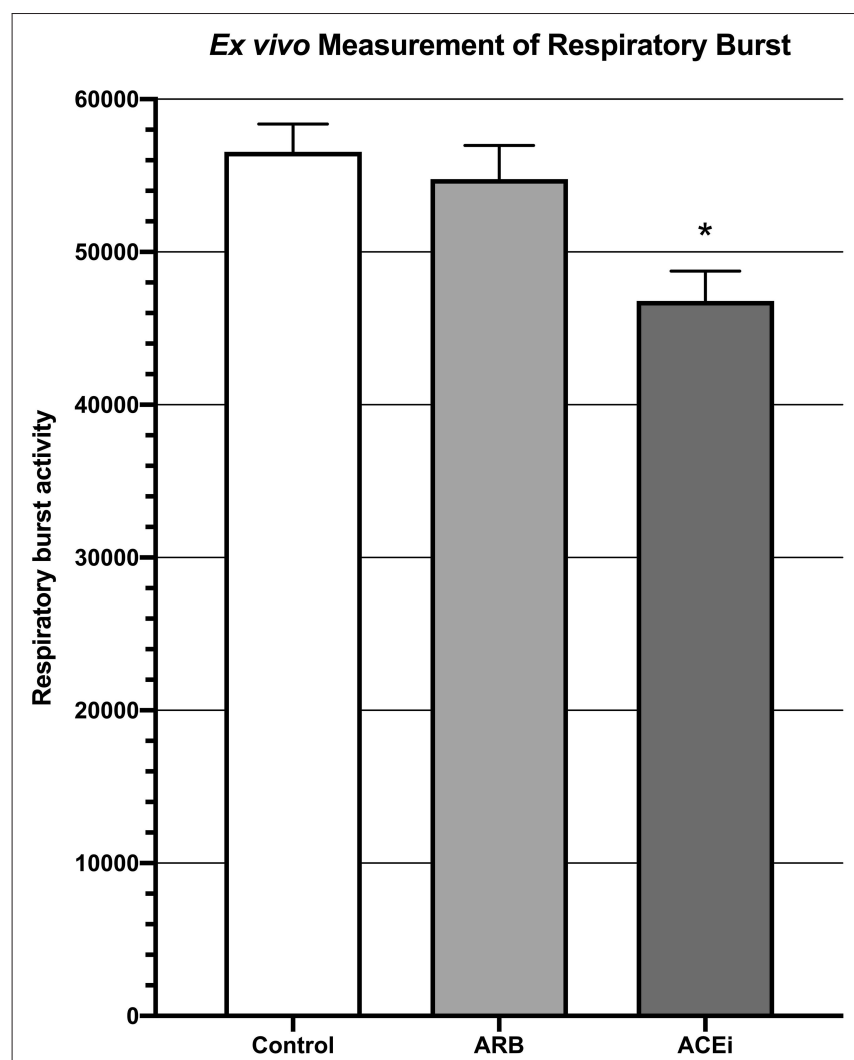

FIGURE 4 | Measurement of respiratory burst ex vivo showing significantly decreased respiratory burst in the blood of mice treated with an ACEi as compared to those treated with an ARB and the untreated control group. ${ }^{*} p<0.05$.

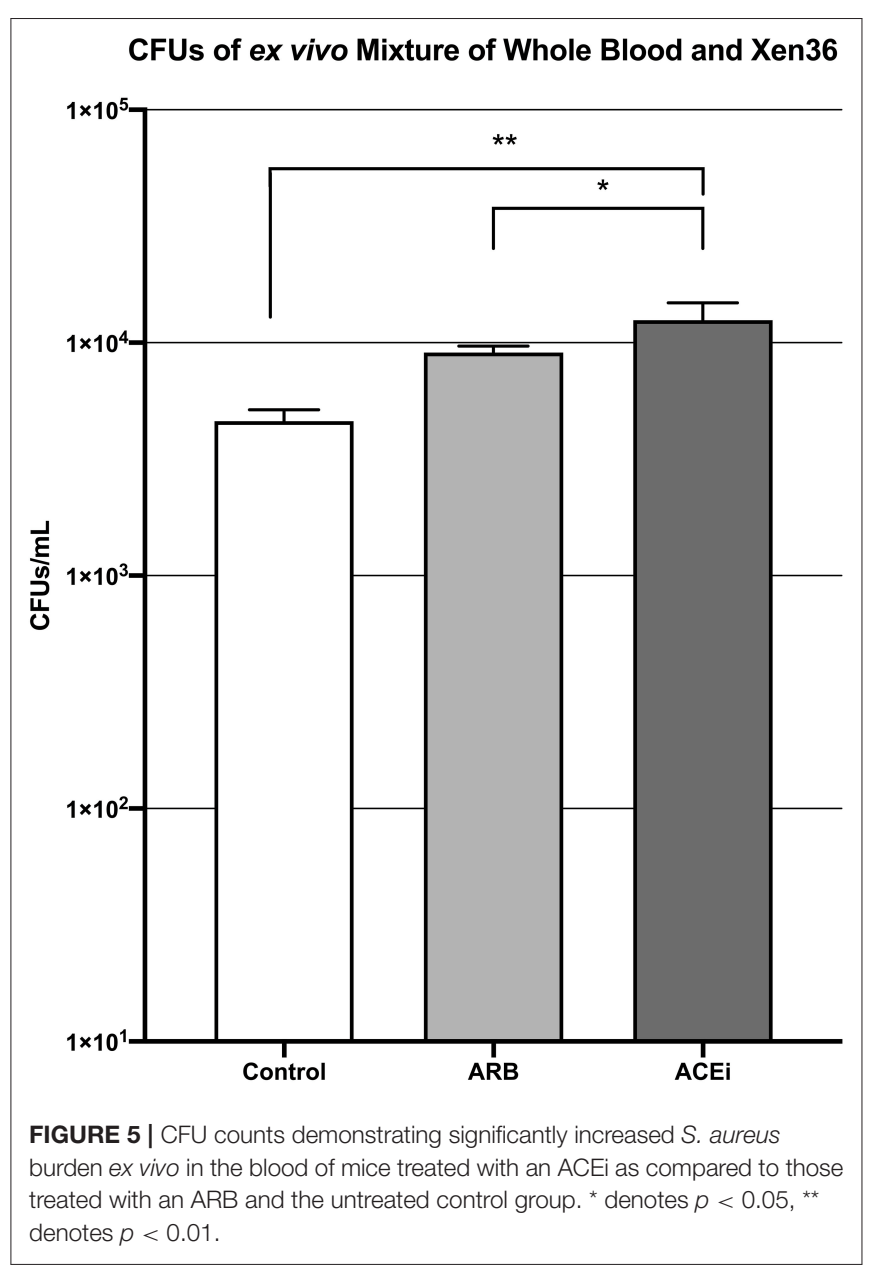

0 and $3(p<0.05)$. The only significant difference between the $\mathrm{ARB}$ and infected control group occurred at POD 14, when the ARB group was significantly higher than the infected control (Figures 7A,B).

Viable $S$. aureus CFUs were identified in 0 of $2(0 \%)$ implants from the sterile control group, 2 of 8 (25\%) implants from the infected control group, 2 of 8 (25\%) implants from the ARB group, and 3 of 8 (37.5\%) implants from the ACEi group. The mean CFU/mL cultured from the harvested implant in the ACEi group $\left(1.1 \times 10^{4} \pm 8.5 \times 10^{3}\right)$ was significantly higher than either the ARB $\left(9.8 \times 10^{2} \pm 7.0 \times 10^{2}\right)$ or infected control groups $(3.3$ $\times 10^{2} \pm 2.9 \times 10^{2}, p<0.05$; Figure 8A).

The mean $\mathrm{CFU} / \mathrm{mL}$ cultured from the excised paraspinal tissue in the ACEi group $\left(1.6 \times 10^{6} \pm 5.1 \times 10^{5}\right)$ was significantly higher than the ARB $\left(6.1 \times 10^{5} \pm 4.2 \times 10^{5}\right)$ and infected control groups $\left(6.4 \times 10^{5} \pm 3.7 \times 10^{5}, p<0.05\right.$; Figure 8B).

\section{Histologic Analysis and Quantification of Monocyte and Neutrophil Infiltration}

Following a review by a board-certified pathologist, there was no qualitative difference in monocyte or neutrophil infiltration to the spleen at POD1 or POD4 between the ACEi, ARB, or control treatment groups based on MPO and F4/80 stains. 

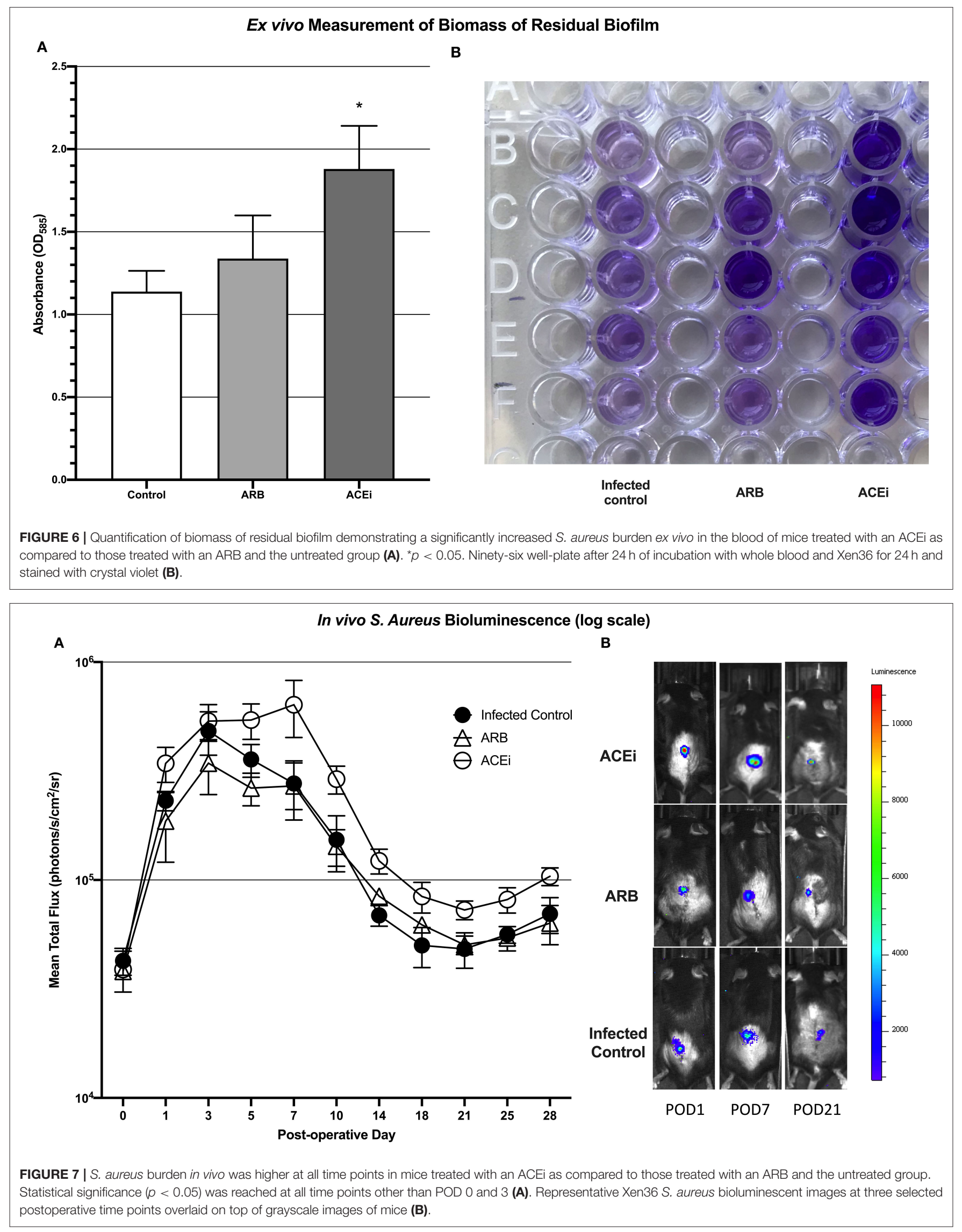


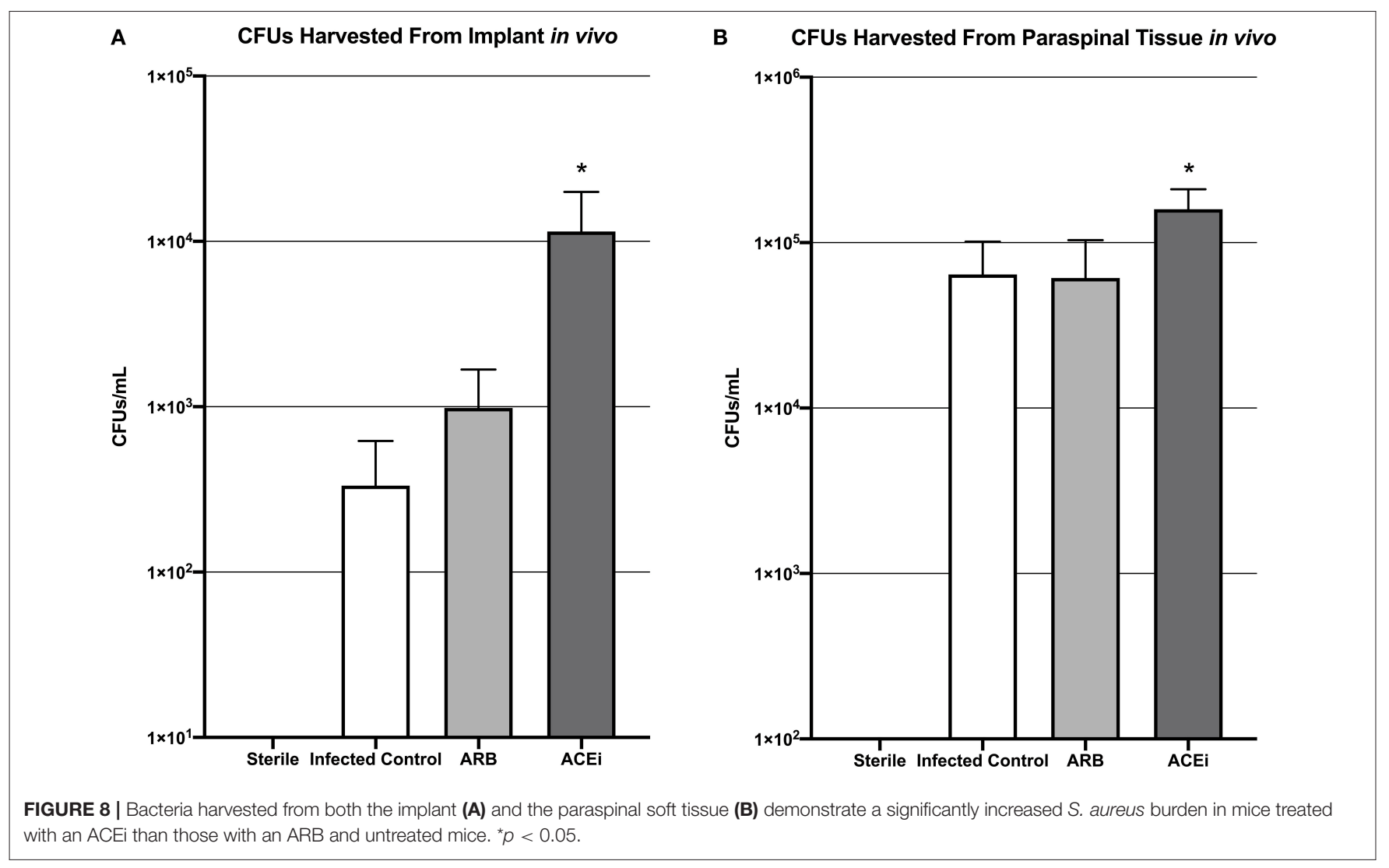

However, there was a qualitative difference in monocyte and neutrophil infiltration to the paraspinal tissue between the groups at POD 4 (Figures 9A,B, 10A,B). The number of nuclei stained at POD 4 per tissue area sum in samples stained with $\mathrm{F} 4 / 80$ was significantly lower in the ACEi group $\left(1.9 \times 10^{-4} \pm 5.6\right.$ $\left.\times 10^{-5}\right)$ compared with both the ARB group $\left(6.0 \times 10^{-4} \pm\right.$ $\left.2.7 \times 10^{-4}\right)$ and the infected control group $\left(5.4 \times 10^{-4} \pm\right.$ $3.9 \times 10^{-4} ; p<0.05$; Figure 9C). The number of cells stained at POD 4 per tissue area sum in samples stained with MPO was significantly lower in the ACEi group vs. the ARB group $\left(1.9 \times 10^{-4} \pm 4.2 \times 10^{-5}\right.$ vs. $3.8 \times 10^{-4} \pm 1.1 \times 10^{-4}$, $p<0.05$; Figure 10C).

\section{DISCUSSION}

Implant-associated SSI is a catastrophic complication. Moreover, staphylococcal species represent roughly two thirds of implantassociated SSI and often compound the issue due to multi-drug resistant phenotypes and a high propensity to form biofilms (65-67). Regardless of implant type, conservative, non-invasive treatment measures frequently fail to eradicate an infection and high-risk surgical intervention is often required $(17,19,20)$. Thus, there is a significant and unmet need to identify modifiable risk factors that may optimize host immune protection against such infections. ACEi and ARB are amongst the most widely prescribed medications, particularly in the aging surgical population $(31,68)$. Given the prevalence of both ACEi and ARB, the potential impact of these therapies could be enormous if they modify immune response or efficacy in ways that subvert host defense.

The current findings first showed that neither ACEi nor ARB had any direct anti-staphylococcal activity in vitro. The rationale behind this in vitro experiment was to show that any purported impact of ACEi or ARB impact on bacterial burden ex vivo or in vivo would not have been due to any anti-staphylococcal effects of the actual therapeutics themselves. This study also shows that blood from mice treated with ACEi demonstrated significantly decreased respiratory burst capacity as well as a significantly decreased ability to suppress $S$. aureus infection ex vivo as compared to ARB-treated or control mice blood. Mice treated with an ACEi also had higher $S$. aureus burden in vivo as measured by bioluminescent signal throughout the entirety of the experiment compared to ARB-treated or infected control groups.

Congruent with these findings, CFU burden measured on implants as well as paraspinal tissue in the ACEi group was significantly higher than either the ARB or infected control groups. Furthermore, viable $S$. aureus CFUs were identified in $37.5 \%$ of the implants in the ACEi group as compared to $25 \%$ in both the ARB and infected control group. Paralleling these microbiologic findings, mice treated with ACEi had significantly decreased monocyte and neutrophil infiltration to the paraspinal tissue on POD 4 compared with infected controls or ARB-treated 


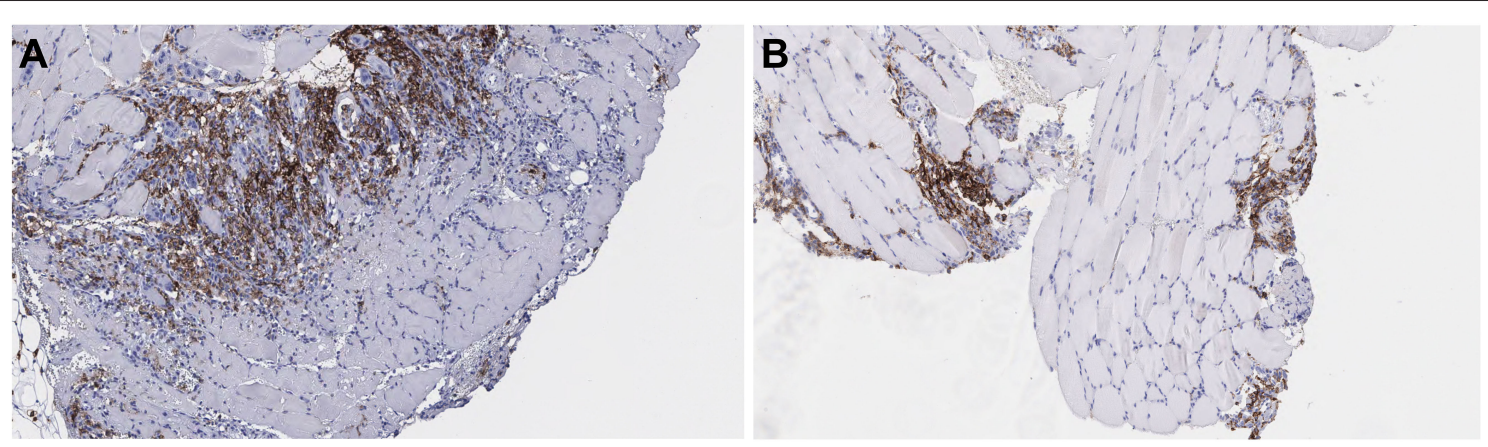

C

In vivo F4/80 Stain of Paraspinal Tissue

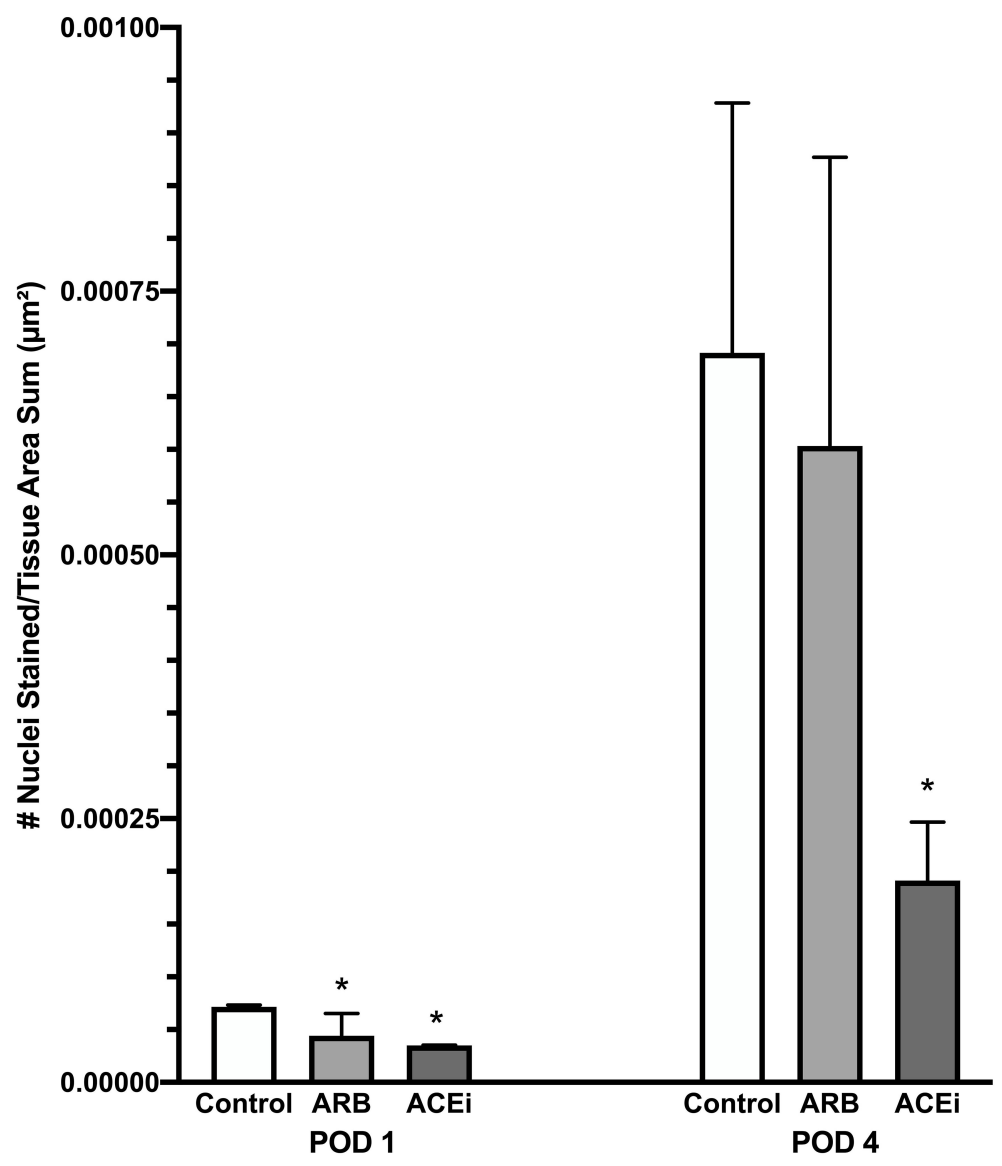

FIGURE 9 | F4/80 stain representing monocyte infiltration to the paraspinal tissue in mice treated with an ARB (A) and an ACEi (B). (C) Mice treated with both an ARB and ACEi had significantly lower levels of monocyte infiltration than the control group at POD 1. Mice treated with an ACEi had significantly lower monocyte infiltration than mice treated with an ARB and the control group at POD 4 (C). ${ }^{*} p<0.05$.

mice. These data suggest that monocyte and neutrophil infiltration and/or functional ROS generation might be impaired by ACEi-related mechanism(s) and may be responsible for the increased susceptibility to $S$. aureus. Taken together, these findings suggest that perioperative ACEi treatment may represent a previously unappreciated risk factor to be considered prior to high-risk surgery such as implant instrumentation.
The increased infectious burden that developed with ACEi treatment is consistent with emerging literature that the reninangiotensin system, and in particular ACE-1, may play an important role in innate pathogen defense (34). Khan et al. (26) recently found that selective neutrophil underexpression of ACE1 markedly increased the susceptibility of mice to cutaneous methicillin resistant S. aureus (MRSA) infection, whereas 

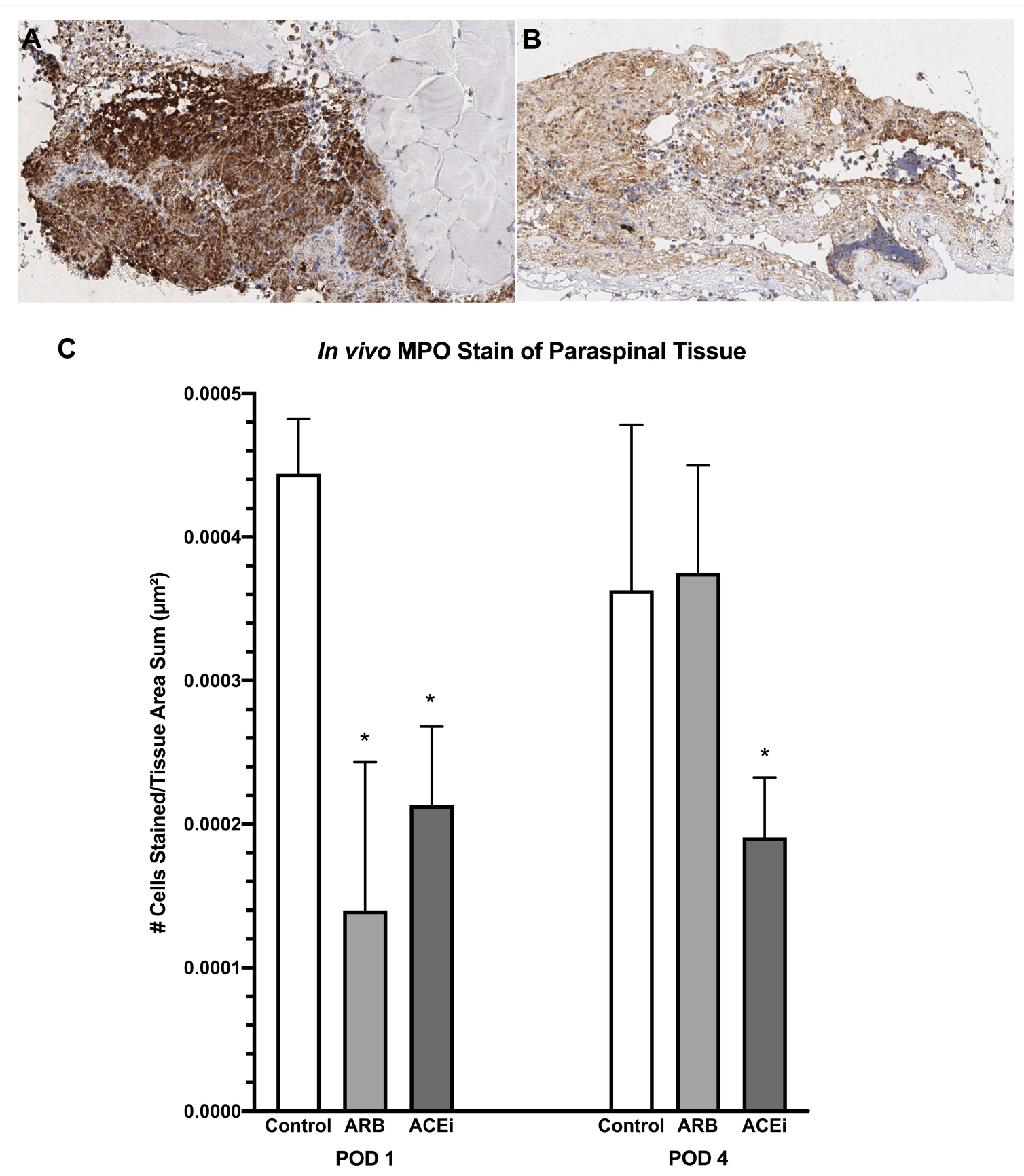

FIGURE 10 | Myeloperoxidase stain representing neutrophil infiltration to the paraspinal tissue in mice treated with an ARB (A) and an ACEi (B). (C) Mice treated with both an ARB and ACEi had significantly lower levels of neutrophil infiltration than the control group at POD 1. Mice treated with an ACEi had significantly lower neutrophil infiltration than mice treated with an ARB and the control group at POD 4 (C). ${ }^{*} p<0.05$.

neutrophil ACE-1 overexpression reduced susceptibility. Similar results have been reported with selective ACE-1 expression modulation in macrophages when challenged with both MRSA and Listeria monocytogenes (40). In both of these studies, the effect of ACE-1 to enhance pathogen clearance appeared angiotensin type-1 receptor independent, consistent with the majority of the results of the present study.
However, other studies implicate the angiotensin type-1 receptor in diverse leukocyte functions including neutrophil chemotaxis (69) as well as natural killer cell proliferation and chemotaxis (70). Activated neutrophils are also a source of angiotensin-II generation, which are produced both ACEdependently and independently (71). In our study, ARB-treated mice treated with ACEi showed significantly higher ex vivo 
CFU counts and significantly lower neutrophil and monocyte infiltration on POD 1 as compared to the infected control group. Therefore, while ARBs may influence pathogen defense-related pathways, these effects appear far less pronounced than ACE1 inhibition. Whether this distinction has clinical relevance warrants future investigation.

There are limitations to this study. It is important to consider the clinical, translational limitations of this implant infection model as it is a simplification of the complex steps involved in human spinal implant surgery. Limitations to this model include being unilateral, involving only the posterior elements of the spine, and use of a single stainless-steel metal implant (53). Furthermore, only S. aureus Xen36 was used in this study. Although this has been shown to be a wellvalidated, representative strain from a clinical isolate (57-59) the authors cannot extrapolate the findings reported to different staphylococcal strains or other microbial organisms. Given that this model allows for a safe, feasible, well-powered, and reproducible way to longitudinally quantify infection in vivo, these advantages are widely viewed to outweigh the accepted limitations. Another limitation to this study is the documented differences between murine and human physiology $(38,72,73)$. Although doses of study therapeutics have been well-established and verified $(40,61)$, dose equivalent adjustments to humans as well as murine-specific pharmacological properties of these therapeutics are further limitations. However, mice treated with ACEi have been shown to respond similarly to humans in that they develop hypotension, increased levels of angiotensin I and decreased levels of ACE expression in myeloid cells (34, 38). Lastly, although this study showed that neither ACEi nor ARB exerted any direct antimicrobial effects on the growth potential of $S$. aureus in vitro, the potential direct effects of these study therapeutics on $S$. aureus metabolism, gene expression and/or virulence in vivo could also contribute to differences in outcomes observed.

The current findings provide ex vivo and in vivo evidence that perioperative ACEi treatment as compared to ARB treatment increases $S$. aureus burden in a manner that corresponds to a reduction in immune effector responses in a longitudinal murine implant infection model. These results in conjunction with the overall body of literature on ACEi immunomodulation suggest that perioperative ACEi treatment could pose additional infectious risks to patients. It is, however, important to consider the balance between any purported immunomodulatory effects of ACEi and its protective cardiovascular effects. ACE inhibition has been shown to improve arterial compliance $(74,75)$ and, by inhibiting angiotensin II formation, decrease left ventricular hypertrophy, generalized coagulability and possibly systemic sympathetic activity in diabetic and hypertensive patients (7678). Therefore, the discontinuation of ACEi perioperatively is not without cardiologic risk. In patients lacking specific indications for particular antihypertensives, ACEi and ARB are often both considered first line therapy (79). Fortunately, ARB have been shown to exert protective cardiovascular effects to a similar, and perhaps greater, extent than ACEi (76, 78, 80, 81). Thus, the cardiovascular sequelae of switching a patient from an ACEi to an ARB perioperatively may not be substantially different.
Moreover, unlike well-established modifiable host risk factors such as obesity and diabetes, switching a patient from ACEi to ARB treatment may be relatively easy, safe, and inexpensive. To this end, it may be possible that certain patients undergoing elective surgery could safely be switched from an ACEi to an $\mathrm{ARB}$ during the perioperative period to minimize any purported infectious risk associated with the immunomodulatory effects of ACEi treatment.

Preoperative host optimization is a key component to mitigating the risk of SSI and its devastating sequelae. The results of this study add to the growing body of literature suggesting that ACEi treatment may represent an under-appreciated, modifiable infectious risk factor. Future clinical studies investigating the relation between SSI and choice of antihypertensives are warranted to help develop guidelines regarding the perioperative use of ACEi.

\section{DATA AVAILABILITY STATEMENT}

The raw data supporting the conclusions of this article will be made available by the authors, without undue reservation.

\section{ETHICS STATEMENT}

The animal study was reviewed and approved by ARC (Animal Research Committee) at the University of California, Los Angeles (UCLA).

\section{AUTHOR CONTRIBUTIONS}

RT, DG, BK, ZM, TS, NC, MY, and NB contributed to conception and design of the study. All experiments were performed by RT, DG, BK, ZM, TS, TO, AC, CM, DL, NC, AS, and NB. Mouse surgical procedures were performed by RT with assistance from DG, BK, ZM, TS, TO, AC, NC, and NB. NC performed the statistical analysis. RT, DG, TS, NC, and DL completed all reference formatting. Figure generation was done by RT, DG, BK, ZM, CM, and NB. RT, DG, BK, ZM, TS, NC, TO, AC, CM, DL, AS, MY, and NB all assisted in writing the first and all subsequent drafts of the manuscript. All authors read and approved the submitted manuscript.

\section{FUNDING}

This work was supported by the National Institute of Arthritis and Musculoskeletal and Skin Diseases of the National Institutes of Health, Award Number 5K08AR069112-01 and the H\&H Lee Research Program. The research presented is the sole responsibility of the authors and does not necessarily represent the official views of the National Institutes of Health.

\section{ACKNOWLEDGMENTS}

The authors would like to acknowledge the UCLA Department of Pathology. Specifically, the Translational Pathology Core Laboratory and Dr. Jonathan Zuckerman, MD, Ph.D. for assistance with histologic imaging and analysis. 


\section{REFERENCES}

1. Ahmed FZ, Fullwood C, Zaman M, Qamruddin A, Cunnington C, Mamas MA, et al. Cardiac implantable electronic device (CIED) infections are expensive and associated with prolonged hospitalisation: UK Retrospective Observational Study. PLoS One. (2019) 14:e0206611. doi: 10.1371/journal.pone.0206611

2. Anderson JM, Marchant RE. Biomaterials: factors favoring colonization and infection, In: Waldvogel FA, Bisno AL, editors. Infections Associated with Biomedical Devices, 3rd ed. ASM Press, Washington DC (2000). p. 89-109.

3. Badia JM, Casey AL, Petrosillo N, Hudson PM, Mitchell SA, Crosby C. Impact of surgical site infection on healthcare costs and patient outcomes: a systematic review in six European countries. J Hosp Infect. (2017) 96:115. doi: 10.1016/j.jhin.2017.03.004

4. Berrios-Torres SI, Umscheid CA, Bratzler DW, Leas B, Stone EC, Kelz $\mathrm{RR}$, et al. Centers for disease control and prevention guideline for the prevention of surgical site infection, 2017. JAMA Surg. (2017) 152:78491. doi: 10.1001/jamasurg.2017.0904

5. Pinto RM, Lopes-de-Campos D, Martins MCL, Van Dijck P, Nunes C, Reis S. Impact of nanosystems in Staphylococcus aureus biofilms treatment. FEMS Microbiol Rev. (2019) 43:622-41. doi: 10.1093/femsre/fuz021

6. Saginur R, Stdenis M, Ferris W, Aaron SD, Chan F, Lee C, et al. Multiple combination bactericidal testing of staphylococcal biofilms from implant-associated infections. Antimicrob Agents Chemother. (2006) 50:5561. doi: 10.1128/AAC.50.1.55-61.2006

7. Shepard J, Ward W, Milstone A, Carlson T, Frederick J, Hadhazy E, et al. Financial impact of surgical site infections on hospitals: the hospital management perspective. JAMA Surg. (2013) 148:907-14. doi: 10.1001/jamasurg.2013.2246

8. Bueno-Lledo J, Torregrosa-Gallud A, Sala-Hernandez A, Carbonell-Tatay F, Pastor PG, Diana SB, et al. Predictors of mesh infection and explantation after abdominal wall hernia repair. Am J Surg. (2017) 213:507. doi: 10.1016/j.amjsurg.2016.03.007

9. Holihan JL, Hannon C, Goodenough C, Flores-Gonzalez JR, Itani $\mathrm{KM}$, Olavarria $\mathrm{O}$, et al. Ventral hernia repair: a meta-analysis of randomized controlled trials. Surg Infect (Larchmt). (2017) 18:64758. doi: 10.1089/sur.2017.029

10. Kurtz SM, Lau E, Schmier J, Ong KL, Zhao K, Parvizi J. Infection burden for hip and knee arthroplasty in the United States. J Arthroplasty. (2008) 23:984-91. doi: 10.1016/j.arth.2007.10.017

11. Kurtz S, Ong K, Lau E, Mowat F, Halpern M. Projections of primary and revision hip and knee arthroplasty in the United States from 2005 to (2030). J Bone Joint Surg Am. (2007) 89:780-5. doi: 10.2106/00004623-200704000-00012

12. McElhinney DB, Sondergaard L, Armstrong AK, Bergersen L, Padera RF, Balzer DT, et al. Endocarditis after transcatheter pulmonary valve replacement. J Am Coll Cardiol. (2018) 72:2717-28. doi: 10.1016/j.jacc.2018.09.039

13. Moussa WM, Mohamed MA. Efficacy of postoperative antibiotic injection in and around ventriculoperitoneal shunt in reduction of shunt infection: a randomized controlled trial. Clin Neurol Neurosurg. (2016) 143:1449. doi: 10.1016/j.clineuro.2016.02.034

14. Perez-Kohler B, Bayon Y, Bellon JM. Mesh infection and hernia repair: a review. Surg Infect (Larchmt). (2016) 17:124-37. doi: 10.1089/sur.2015.078

15. Rosenthal VD, Richtmann R, Singh S, Apisarnthanarak A, Kubler A, VietHung N, et al. Surgical site infections, International Nosocomial Infection Control Consortium (INICC) report, data summary of 30 countries, 20052010. Infect Control Hosp Epidemiol. (2013) 34:597-604. doi: 10.1086/ 670626

16. Summers MR, Leon MB, Smith CR, Kodali SK, Thourani VH, Herrmann HC, et al. Prosthetic valve endocarditis after TAVR and SAVR: insights from the PARTNER trials. Circulation. (2019) 140:1984-94. doi: 10.1161/CIRCULATIONAHA.119.041399

17. Pelegrin I, Lora-Tamayo J, Gomez-Junyent J, Sabe N, Garcia-Somoza D, Gabarros A, et al. Management of ventriculoperitoneal shunt infections in adults: analysis of risk factors associated with treatment failure. Clin Infect Dis. (2017) 64:989-97. doi: 10.1093/cid/cix005
18. Sinha I, Pusic AL, Wilkins EG, Hamill JB, Chen X, Kim HM, et al. Late surgical-site infection in immediate implant-based breast reconstruction. Plast Reconstr Surg. (2017) 139:20-8. doi: 10.1097/PRS.0000000000002839

19. Baddour LM, Epstein AE, Erickson CC, Knight BP, Levison $\mathrm{ME}$, Lockhart $\mathrm{PB}$, et al. Update on cardiovascular implantable electronic device infections and their management: a scientific statement from the American Heart Association. Circulation. (2010) 121:458-77. doi: 10.1161/CIRCULATIONAHA.109.192665

20. Kowalski TJ, Berbari EF, Huddleston PM, Steckelberg JM, Mandrekar JN, Osmon DR. The management and outcome of spinal implant infections: contemporary retrospective cohort study. Clin Infect Dis. (2007) 44:91320. doi: 10.1086/512194

21. Surveillance, Epidemiology, and End Results (SEER) Program. SEER*Stat Database: Incidence - SEER Research Data, 9 Registries. (2019). Sub (19752017). Available online at: www.seer.cancer.gov/statfacts/ (accessed April 30, 2020).

22. Akbari M, Fararouei M, Haghdoost AA, Gouya MM, Kazerooni PA. Survival and associated factors among people living with HIV/AIDS: a 30-year national survey in Iran. J Res Med Sci. (2019) 24:5. doi: 10.4103/jrms.JRMS_630_18

23. Kurtz SM, Lau EC, Son MS, Chang ET, Zimmerli W, Parvizi J. Are we winning or losing the battle with periprosthetic joint infection: trends in periprosthetic joint infection and mortality risk for the medicare population. J Arthroplasty. (2018) 33:3238-45. doi: 10.1016/j.arth.2018.05.042

24. Liu ZQ, Zhou N, Bai JY, Guo Y, Yu MH. [Analysis of survival and influencing factors of HIV/AIDS patients in Tianjin, 2004-2014]. Zhonghua Liu Xing Bing Xue Za Zhi. (2017) 38:369-73. doi: 10.3760/cma.j.issn.0254-6450.2017.03.019

25. Zmistowski B, Karam JA, Durinka JB, Casper DS, Parvizi J. Periprosthetic joint infection increases the risk of one-year mortality. J Bone Joint Surg Am. (2013) 95:2177-84. doi: 10.2106/JBJS.L.00789

26. Khan Z, Shen XZ, Bernstein EA, Giani JF, Eriguchi M, Zhao $\mathrm{TV}$, et al. Angiotensin-converting enzyme enhances the oxidative response and bactericidal activity of neutrophils. Blood. (2017) 130:328-39. doi: 10.1182/blood-2016-11-752006

27. Kostis WJ, Shetty M, Chowdhury YS, Kostis JB. ACE inhibitorinduced angioedema: a review. Curr Hypertens Rep. (2018) 20:55. doi: 10.1007/s11906-018-0859-x

28. Mentz RJ, Bakris GL, Waeber B, McMurray JJ, Gheorghiade M, Ruilope LM, et al. The past, present and future of renin-angiotensin aldosterone system inhibition. Int J Cardiol. (2013) 167:1677-87. doi: 10.1016/j.ijcard.2012.10.007

29. Rincon-Choles H. ACE inhibitor and ARB therapy: Practical recommendations. Cleve Clin J Med. (2019) 86:60811. doi: $10.3949 /$ ccjm.86a.19016

30. Agency for Healthcare Research and Quality. Number of People With Purchase in Thousands by Prescribed Drug, United States, 2010-2017. Medical Expenditure Panel Survey (2020).

31. Hales CM, Servais J, Martin CB, Kohen D. Prescription drug use among adults aged 40-79 in the United States and Canada. NCHS Data Brief. (2019) 247:1-8.

32. Roshanov PS, Rochwerg B, Patel A, Salehian O, Duceppe E, BelleyCote EP, et al. Withholding versus continuing angiotensin-converting enzyme inhibitors or angiotensin II receptor blockers before noncardiac surgery: an analysis of the vascular events in noncardiac surgery patIents cOhort evaluation prospective cohort. Anesthesiology. (2017) 126:1627. doi: 10.1097/ALN.0000000000001404

33. Benigni A, Cassis P, Remuzzi G. Angiotensin II revisited: new roles in inflammation, immunology and aging. EMBO Mol Med. (2010) 2:24757. doi: 10.1002/emmm.201000080

34. Bernstein KE, Khan Z, Giani JF, Cao DY, Bernstein EA, Shen XZ. Angiotensinconverting enzyme in innate and adaptive immunity. Nat Rev Nephrol. (2018) 14:325-36. doi: 10.1038/nrneph.2018.15

35. Cao DY, Spivia WR, Veiras LC, Khan Z, Peng Z, Jones AE, et al. ACE overexpression in myeloid cells increases oxidative metabolism and cellular ATP. J Biol Chem. (2020) 295:1369-84. doi: 10.1074/jbc.RA119.011244

36. Crowley SD, Rudemiller NP. Immunologic effects of the renin-angiotensin system. J Am Soc Nephrol. (2017) 28:1350-61. doi: 10.1681/ASN.2016101066

37. Dial S, Nessim SJ, Kezouh A, Benisty J, Suissa S. Antihypertensive agents acting on the renin-angiotensin system and the risk of sepsis. $\mathrm{Br} J$ Clin Pharmacol. (2014) 78:1151-8. doi: 10.1111/bcp.12419 
38. Gonzalez-Villalobos RA, Shen XZ, Bernstein EA, Janjulia T, Taylor B, Giani JF, et al. Rediscovering ACE: novel insights into the many roles of the angiotensin-converting enzyme. J Mol Med (Berl). (2013) 91:114354. doi: 10.1007/s00109-013-1051-Z

39. Gullestad L, Aukrust P, Ueland T, Espevik T, Yee G, Vagelos R, et al. Effect of high- versus low-dose angiotensin converting enzyme inhibition on cytokine levels in chronic heart failure. J Am Coll Cardiol. (1999) 34:20617. doi: 10.1016/S0735-1097(99)00495-7

40. Okwan-Duodu D, Datta V, Shen XZ, Goodridge HS, Bernstein EA, Fuchs S, et al. Angiotensin-converting enzyme overexpression in mouse myelomonocytic cells augments resistance to Listeria and methicillin-resistant Staphylococcus aureus. J Biol Chem. (2010) 285:39051-60. doi: 10.1074/jbc.M110.163782

41. Platten M, Youssef S, Hur EM, Ho PP, Han MH, Lanz TV, et al. Blocking angiotensin-converting enzyme induces potent regulatory $\mathrm{T}$ cells and modulates TH1- and TH17-mediated autoimmunity. Proc Natl Acad Sci U S A. (2009) 106:14948-53. doi: 10.1073/pnas.0903958106

42. Shen XZ, Billet S, Lin C, Okwan-Duodu D, Chen X, Lukacher AE, et al. The carboxypeptidase ACE shapes the MHC class I peptide repertoire. Nat Immunol. (2011) 12:1078-85. doi: 10.1038/ni.2107

43. Shen XZ, Li P, Weiss D, Fuchs S, Xiao HD, Adams JA, et al. Mice with enhanced macrophage angiotensin-converting enzyme are resistant to melanoma. Am J Pathol. (2007) 170:2122-34. doi: 10.2353/ajpath.2007.061205

44. Shen XZ, Lukacher AE, Billet S, Williams IR, Bernstein KE. Expression of angiotensin-converting enzyme changes major histocompatibility complex class I peptide presentation by modifying $\mathrm{C}$ termini of peptide precursors. $J$ Biol Chem. (2008) 283:9957-65. doi: 10.1074/jbc.M709574200

45. Veiras LC, Cao D, Saito S, Peng Z, Bernstein EA, Shen JZY, et al. Overexpression of ACE in myeloid cells increases immune effectiveness and leads to a new way of considering inflammation in acute and chronic diseases. Curr Hypertens Rep. (2020) 22:4. doi: 10.1007/s11906-019-1008-x

46. Zhao T, Bernstein KE, Fang J, Shen XZ. Angiotensin-converting enzyme affects the presentation of MHC class II antigens. Lab Invest. (2017) 97:76471. doi: 10.1038/labinvest.2017.32

47. Chen K, Wei Y, Sharp GC, Braley-Mullen H. Inhibition of TGF $\beta 1$ by anti-TGF $\beta 1$ antibody or lisinopril reduces thyroid fibrosis in granulomatous experimental autoimmune thyroiditis. J Immunol. (2002) 169:6530-8. doi: 10.4049/jimmunol.169.11.6530

48. Nakamura A, Johns EJ, Imaizumi A, Yanagawa Y, Kohsaka T. Effect of $\beta(2)$ adrenoceptor activation and angiotensin II on tumour necrosis factor and interleukin 6 gene transcription in the rat renal resident macrophage cells. Cytokine. (1999) 11:759-65. doi: 10.1006/cyto.1999.0488

49. Constantinescu CS, Goodman DB, Ventura ES. Captopril and lisinopril suppress production of interleukin-12 by human peripheral blood mononuclear cells. Immunol Lett. (1998) 62:25-31. doi: 10.1016/S0165-2478(98)00025-X

50. Aida T, Furukawa K, Suzuki D, Shimizu H, Yoshidome H, Ohtsuka M, et al. Preoperative immunonutrition decreases postoperative complications by modulating prostaglandin E2 production and T-cell differentiation in patients undergoing pancreatoduodenectomy. Surgery. (2014) 155:12433. doi: 10.1016/j.surg.2013.05.040

51. Evans DC, Martindale RG, Kiraly LN, Jones CM. Nutrition optimization prior to surgery. Nutr Clin Pract. (2014) 29:10-21. doi: 10.1177/0884533613517006

52. Fragiadakis GK, Gaudilliere B, Ganio EA, Aghaeepour N, Tingle M, Nolan GP, et al. Patient-specific immune states before surgery are strong correlates of surgical recovery. Anesthesiology. (2015) 123:124155. doi: 10.1097/ALN.0000000000000887

53. Dworsky EM, Hegde V, Loftin AH, Richman S, Hu Y, Lord E, et al. Novel in vivo mouse model of implant related spine infection. J Orthop Res. (2017) 35:193-9. doi: 10.1002/jor.23273

54. Hegde V, Park HY, Dworsky E, Zoller SD, Xi W, Johansen DO, et al. The use of a novel antimicrobial implant coating in vivo to prevent spinal implant infection. Spine. (2018) 45:1. doi: 10.1097/BRS.0000000000 003279

55. Park HY, Hegde V, Zoller SD, Sheppard W, Hamad C, Smith RA, et al. Progress not panacea: vancomycin powder efficacy and dose evaluated in an in vivo mouse model of spine implant infection. Spine J. (2019) 20:97380. doi: 10.1016/j.spinee.2019.12.007
56. Zoller SD, Park HY, Olafsen T, Zamilpa C, Burke ZD, Blumstein $\mathrm{G}$, et al. Multimodal imaging guides surgical management in a preclinical spinal implant infection model. JCI Insight. (2019) 4:e124813. doi: 10.1172/jci.insight.124813

57. Bernthal NM, Stavrakis AI, Billi F, Cho JS, Kremen TJ, Simon SI, et al. A mouse model of post-arthroplasty Staphylococcus aureus joint infection to evaluate in vivo the efficacy of antimicrobial implant coatings. PLoS One. (2010) 5:e12580. doi: 10.1371/journal.pone.0012580

58. Francis KP, Joh D, Bellinger-Kawahara C, Hawkinson MJ, Purchio TF, Contag PR. Monitoring bioluminescent Staphylococcus aureus infections in living mice using a novel luxABCDE construct. Infect Immun. (2000) 68:3594600. doi: 10.1128/IAI.68.6.3594-3600.2000

59. Pribaz JR, Bernthal NM, Billi F, Cho JS, Ramos RI, Guo Y, et al. Mouse model of chronic post-arthroplasty infection: noninvasive in vivo bioluminescence imaging to monitor bacterial burden for long-term study. J Orthop Res. (2012) 30:335-40. doi: 10.1002/jor.21519

60. Hudzicki J. Kirby Bauer Diffusion Susceptibility Test Protocol. American Society for Microbiology (ASM). Retrieved from: https://www.asmscience. org/content/education/protocol/protocol.3189?crawler=true (accessed February 18, 2020)

61. Lazaro A, Gallego-Delgado J, Justo P, Esteban V, Osende J, Mezzano S, et al. Long-term blood pressure control prevents oxidative renal injury. Antioxid Redox Signal. (2005) 7:1285-93. doi: 10.1089/ars.2005.7.1285

62. Doll K, Jongsthaphongpun KL, Stumpp NS, Winkel A, Stiesch M. Quantifying implant-associated biofilms: comparison of microscopic, microbiologic and biochemical methods. J Microbiol Methods. (2016) 130:61-8. doi: 10.1016/j.mimet.2016.07.016

63. Extremina CI, Costa L, Aguiar AI, Peixe L, Fonseca AP. Optimization of processing conditions for the quantification of enterococci biofilms using microtitre-plates. J Microbiol Methods. (2011) 84:167-73. doi: 10.1016/j.mimet.2010.11.007

64. Xu Z, Liang Y, Lin S, Chen D, Li B, Li L, et al. Crystal violet and XTT assays on Staphylococcus aureus biofilm quantification. Curr Microbiol. (2016) 73:474-82. doi: 10.1007/s00284-016-1081-1

65. Oliveira WF, Silva PMS, Silva RCS, Silva GMM, Machado G, Coelho L, et al. Staphylococcus aureus and Staphylococcus epidermidis infections on implants. J Hosp Infect. (2018) 98:111-7. doi: 10.1016/j.jhin.2017.11.008

66. Patel H, Khoury H, Girgenti D, Welner S, Yu H. Burden of surgical site infections associated with select spine operations and involvement of Staphylococcus aureus. Surg Infect (Larchmt). (2017) 18:461-73. doi: 10.1089/sur.2016.186

67. Tarakji KG, Wilkoff BL. Antibacterial envelope to prevent cardiac implantable device infection. Reply. $N$ Engl J Med. (2019) 381:1783-4. doi: 10.1056/NEJMc1908355

68. Schimmel JJ, Horsting PP, de Kleuver M, Wonders G, van Limbeek J. Risk factors for deep surgical site infections after spinal fusion. Eur Spine J. (2010) 19:1711-9. doi: 10.1007/s00586-010-1421-y

69. Nabah YN, Mateo T, Estelles R, Mata M, Zagorski J, Sarau H, et al. Angiotensin II induces neutrophil accumulation in vivo through generation and release of CXC chemokines. Circulation. (2004) 110:3581-6. doi: 10.1161/01.CIR.0000148824.93600.F3

70. Jurewicz M, McDermott DH, Sechler JM, Tinckam K, Takakura A, Carpenter CB, et al. Human $\mathrm{T}$ and natural killer cells possess a functional renin-angiotensin system: further mechanisms of angiotensin II-induced inflammation. J Am Soc Nephrol. (2007) 18:1093-102. doi: 10.1681/ASN.2006070707

71. Owen CA, Campbell EJ. Angiotensin II generation at the cell surface of activated neutrophils: novel cathepsin G-mediated catalytic activity that is resistant to inhibition. J Immunol. (1998) 160:1436-43.

72. Chegary M, Brinke H, Ruiter JP, Wijburg FA, Stoll MS, Minkler PE, et al. Mitochondrial long chain fatty acid beta-oxidation in man and mouse. Biochim Biophys Acta. (2009) 1791:806-15. doi: 10.1016/j.bbalip.2009. 05.006

73. King-Underwood L, Little S, Baker M, Clutterbuck R, Delassus S, Enver T, et al. Wt1 is not essential for hematopoiesis in the mouse. Leuk Res. (2005) 29:803-12. doi: 10.1016/j.leukres.2004.11.020

74. McFarlane SI, Kumar A, Sowers JR. Mechanisms by which angiotensinconverting enzyme inhibitors prevent diabetes and cardiovascular 
disease. Am J Cardiol. (2003) 91:30H-7H. doi: 10.1016/S0002-9149(03) 00432-6

75. Winer N, Weber MA, Sowers JR. The effect of antihypertensive drugs on vascular compliance. Curr Hypertens Rep. (2001) 3:297-304. doi: 10.1007/s11906-001-0092-9

76. Klein IH, Ligtenberg G, Oey PL, Koomans HA, Blankestijn PJ. Enalapril and losartan reduce sympathetic hyperactivity in patients with chronic renal failure. $J$ Am Soc Nephrol. (2003) 14:425-30. doi: 10.1097/01.ASN.0000045049. 72965.B7

77. Schmieder RE, Hilgers KF, Schlaich MP, Schmidt BM. Reninangiotensin system and cardiovascular risk. Lancet. (2007) 369:1208-19. doi: 10.1016/S0140-6736(07)60242-6

78. Tsuda K. Renin-Angiotensin system and sympathetic neurotransmitter release in the central nervous system of hypertension. Int J Hypertens. (2012) 2012:474870. doi: 10.1155/2012/474870

79. Whelton PK, Carey RM, Aronow WS, Casey DE Jr, Collins KJ, Dennison Himmelfarb C, et al. 2017 ACC/AHA/AAPA/ABC/ACPM/AGS/APhA/ASH/ASPC/NMA/PCNA guideline for the prevention, detection, evaluation, and management of high blood pressure in adults: executive summary: a report of the American College of Cardiology/American Heart Association Task Force on Clinical Practice Guidelines. Hypertension. (2018) 71:1269-324. doi: 10.1161/HYP.0000000000 000075
80. Ferrari R, Boersma E. The impact of ACE inhibition on all-cause and cardiovascular mortality in contemporary hypertension trials: a review. Expert Rev Cardiovasc Ther. (2013) 11:705-17. doi: 10.1586/erc.13.42

81. Misra S, Stevermer JJ. ACE inhibitors and ARBs: one or the other-not both-for high-risk patients. J Fam Pract. (2009) 58:24-7.

Conflict of Interest: NB and MY have or may receive grant support or related benefits from the National Institutes of Health. MY receives grant support from the U.S. Department of Defense, and is founder and shareholder of NovaDigm Therapeutics, Inc., which develops novel vaccines and immunotherapeutics targeting infection.

The remaining authors declare that the research was conducted in the absence of any commercial or financial relationships that could be construed as a potential conflict of interest.

Copyright (C) 2020 Trikha, Greig, Kelley, Mamouei, Sekimura, Cevallos, Olson, Chaudry, Magyar, Leisman, Stavrakis, Yeaman and Bernthal. This is an open-access article distributed under the terms of the Creative Commons Attribution License (CC $B Y)$. The use, distribution or reproduction in other forums is permitted, provided the original author(s) and the copyright owner(s) are credited and that the original publication in this journal is cited, in accordance with accepted academic practice. No use, distribution or reproduction is permitted which does not comply with these terms. 